\title{
Correction to: On the impact of correlations on the congruence test: a bootstrap approach
}

\section{Case study: B-spline surface fitting from TLS observations}

\author{
Kermarrec Gaël ${ }^{1}$ D $\cdot$ Kargoll Boris ${ }^{2}$. Alkhatib Hamza ${ }^{1}$
}

Published online: 18 September 2020

C) Akadémiai Kiadó 2020

\section{Correction to: Acta Geodaetica et Geophysica (2020) 55:495-513 https://doi.org/10.1007/s40328-020-00302-8}

In the article On the impact of correlations on the congruence test: a bootstrap approach, Table 1 should be corrected to:

These changes do not affect the conclusions of the data analysis. We apologize for the mistake.

Table $1\left[\sigma_{I M F 1}, \sigma_{I M F 2+3}, \alpha, \nu\right]$ for L8 and L10 are computed for the first load step E00. The standard deviation is given in $[\mathrm{mm}]$

\begin{tabular}{llll}
\hline $\mathrm{L} 8$ & {$\left[\sigma_{I M F 1}, \sigma_{I M F 2+3}, \alpha, v\right]$} & $\mathrm{L} 10$ & {$\left[\sigma_{I M F 1}, \sigma_{I M F 2+3}, \alpha, \nu\right]$} \\
\hline E00 & {$[0.5,0.3,1.20,2.2]$} & E00 & {$[0.7,0.3,1.58,1.01]$} \\
\hline
\end{tabular}

The original article can be found online at https://doi.org/10.1007/s40328-020-00302-8.

Kermarrec Gaël

kermarrec@gih.uni-hannover.de

Kargoll Boris

kargoll@hs-anhalt.de

Alkhatib Hamza

alkhatib@gih.uni-hannover.de

1 Geodetic Institute, Leibniz Universität Hannover, Nienburger Str. 1, 30167 Hannover, Germany

2 Institut für Geoinformation und Vermessung Dessau, Anhalt University of Applied Sciences, Seminarplatz 2a, 06846 Dessau, Germany 